\title{
Rectal Squamous Cell Carcinoma
}

National Cancer Institute

\section{Source}

National Cancer Institute. Rectal Squamous Cell Carcinoma. NCI Thesaurus. Code C5554.

A very rare rectal carcinoma characterized by the presence of a malignant squamous cell infiltrate. 